\title{
ANALYSIS OF EARLY RELAPAROTOMY IN OBSTETRIC \& GYNAECOLOGICAL SURGERIES
}

\author{
Shumaila Zia, ${ }^{1}$ Muhammad Rafique, ${ }^{2}$ Muhammad Atif Qureshi, ${ }^{3}$ Baha Ahmad ${ }^{4}$
}

\begin{abstract}
Objectives: Evaluation of risk factors, frequency, causes and measures took to save patients' life in relaparotomies.

Methods: This retrospective, descriptive study was conducted from January 2012 - December 2014 in a tertiary care hospital.

Results: This study includes 38 cases, 29 (76.3\%) obstetrical and nine $(23.7 \%)$ gynaecological Relaparotomy incidence was $0.43 \%$. It was $0.55 \%$ for obstetrical and $0.24 \%$ for gynaecological indications. The leading causes were suspected intra-abdominal bleeding in $24(63.2 \%)$, uncontrolled postpartum haemorrhage (PPH) in nine (23.7\%) and suspected abdominal
\end{abstract}

\section{Zia S. ${ }^{1}$}

Associate Professor, Department of Obstetrics and Gynaecology, Azra Naheed Medical College/ Superior University, Lahore

Rafique M. ${ }^{2}$

Associate Professor, Department of Paediatrics

FJMU / Sir Ganga Ram Hospital, Lahore

Qureshi M.A. ${ }^{3}$

Associate Professor, Department of Medicine

Azra Naheed Medical College / Superior University, Lahore

Ahmad B. ${ }^{4}$

Assistant Professor, Department of Obstetrics and Gynaecology, College of Medicine, King Khalid University Abha, KSA wall bleeding in five $(13.15 \%)$ cases. Major risk factor in gynaecological cases was evacuation and curettage (55.5\%). In obstetric patients risk factor was previous caesarean sections (CS) 28/29(96.5\%). Of 28 previous CS cases, multiple CS were in13 (46.4\%), placenta previa in five $(17.85 \%)$ and antepartum hemorrhage in four $(14.28 \%)$ cases. Majority $(92.1 \%)$ of patients underwent relaparotomy within 24 hours after primary surgery. Patients received (mean \pm SD) $7.2 \pm 5.4$ packed red blood cells, $4.3 \pm 5.5$ fresh frozen plasma and $1.2 \pm 2.3$ platelets units. Third operation was needed in seven $(18.4 \%)$ cases. Twelve (31.6\%) women developed complications. There were three $(7.9 \%)$ maternal deaths following relaparotomy.

Conclusion: Intra-abdominal bleeding is main cause for re-operation and multiple CS is major risk factor. Recognition of risk factors, careful primary operation, involvement of seniors in complicated surgeries and early intervention can prevent majority of the relaparotomies.

Key words: Relaparotomy, reoperation, complicated caesarean section, maternal mortality, obstetrics and gynaecology, intra-peritoneal haemorrhage.

\section{Introduction}

In obstetric specialty emergency surgeries are frequently done. Some risks and complication are commonly associated with major surgeries. Lack of a need to repeat the surgery is an indicator of successful primary operation. A reoperation incidence of $0.6-4.7 \%$ has been encountered in various studies. ${ }^{1,2}$ In some 
cases, the complications of primary surgery force to do relaparotomy. Obviously the purpose of reoperation is to manage the complications of primary procedure, maintain haemostasis, prevent intra-abdominal infections and perform curative surgery. ${ }^{3}$ Very frequently, reoperation is carried out when the condition of the patient is very critical. Relaparotomy is a difficult and challenging decision and needs good clinical judgment. Reoperation may be considered as a near miss maternal mortality situation ${ }^{4}$ so, it should be carried out by expert surgeons. ${ }^{5,6}$ Intra-abdominal and postpartum haemorrhage, rectus sheath haematoma, sepsis and small bowel obstruction had been observed the leading causes of relaparotomy. ${ }^{4}$

In view of all these findings we planned a study in our set-up. The aims of the present study were: firstly to find out the risk factors, frequency, causes and procedures done to save patients' life during relaparotomy. Secondly, to analyze our constraints to convene a remedy too.

\section{Material and Methods}

It was a retrospective descriptive study. All records of exploratory laparotomy from January 2012 - December 2014 in a tertiary care hospital, Kingdom of Saudi Arabia were retrieved. During the study period, a total of 8820 obstetrics and gynaecological operations were performed. All the cases needed relaparotomy were included in the study. Reoperation was required in 38 patients and the incidence was found $0.4 \%$. Of these 38 cases, 29 had primary operations in this hospital while nine had primary surgery at other hospitals/private clinics of Abha city and nearby areas. This institution has a large catchment area. Various public and private hospitals/clinics in the city and from nearby peri-urban and rural areas refer their critical patients to this tertiary care hospital. We recorded various demographics and obstetric variables like age, gravidity, parity, prior miscarriages, indications of primary operation and relaparotomy, time interval between first and second surgery, procedure performed on reoperation, average blood loss in both primary and secondary operation, units of blood/blood products transfused, hospital stay and the outcome of repeat surgery. We divided the cases into two groups according to time interval ( $<10$ hours and $>10$ hours) between first and second operation for comparison, to analyze the results of early and late reoperation decision. This hospital is a teaching and training institute, so caesarean delive- ries are usually performed by specialist or post graduate trainees under direct supervision of specialists, consultants and professors. Relaparotomies once needed were done by consultants and professors.

For data entry and analyses, SPSS version 22 was used. Descriptive statistics were analyzed by mean, standard deviation, range and percentage. Clinical data were compared by using unpaired " $t$ test" for normally distributed continuous variables. Statistically signifycant value was $p<0.05$. The study was approved by the Research and Ethics Committee of the university.

\section{Results}

During three years study period, 8820 procedures were performed. Of them, $38(0.43 \%)$ were followed by exploratory re-laparotomy. For obstetric conditions, out of 5184 operation, $29(0.55 \%)$ women required reoperation. For gynaecological indications, out of 3636 surgeries, $9(0.24 \%)$ patients went for relaparotomy.

The mean age of the patients was 34 (range: 17 $75)$ years. The mean gravidity was 3 and parity was 4 . The mean gestational age in obstetric patients was 37 weeks. Most common complication requiring re-laparotomy was intra-peritoneal haemorrhage. Most of the women 35/38 (92.1\%) underwent relaparotomy during first 24 hours and two within $24-96$ hours after primary surgery. Only one patient had reoperation after 4 days who recovered smoothly.

Indications for reoperation noted were, suspicion of intra-abdominal bleeding in $24(63.15 \%)$, uncontrolled postpartum haemorrhage $(\mathrm{PPH})$ in nine $(23.7 \%)$ and suspected abdominal wall bleeding in five (13.15\%) cases. On the basis of clinical judgment, the decisions of reoperations were taken by consultants on call.

Of 29 obstetric patients, $28(96.5 \%)$ had caesarean delivery and one had vaginal birth after CS. Of $28 \mathrm{CS}$, $13(46.4 \%)$ had $\geq 2$ previous CS in labour or elective. In five $(17.85 \%)$ cases indication of primary operation was placenta previa, four (14.3\%) patients presented with complaint of vaginal bleeding so, in suspicion of scar dehiscence, CS was done, two $(7.14 \%)$ patients each had CS for fetal distress, failed induction and failure of progress.

In gynaecological cases, nine relaparotomies were performed. Of them, five $(55.5 \%)$ were because of bleeding following evacuation and curettage (E\&C). The indications for $\mathrm{E} \& \mathrm{C}$ were, retained products of 
conception inside the uterus in three cases while two cases had septic endometritis and fibroid uterus. All these cases were referred from outside the hospital. Two $(22.2 \%)$ cases each had relaparotomy after total abdominal hysterectomy and oophorectomy.

Table 1 shows intra-operative findings of re-laparotomy. Oozing of blood from the uterine scar was found the most common in $14(36.8 \%)$. No relaparotomy was performed for septic wound dehiscence.

Table 1: Intra-operative findings of relaparotomy $(n=38)$.

\begin{tabular}{|l|c|c|}
\hline Intra operative findings & $\begin{array}{c}\text { Patient } \\
\mathrm{n}=38\end{array}$ & Percentage \\
\hline Uterine scar bleeding & 12 & 31.5 \\
\hline Broad ligament haematoma & 8 & 21.1 \\
\hline Loose knots of pedicles & 5 & 13.2 \\
\hline $\begin{array}{l}\text { Rectus muscle and sheath } \\
\text { haematoma }\end{array}$ & 5 & 13.2 \\
\hline Generalized oozing & 4 & 10.5 \\
\hline Bleeding from lower cervix & 3 & 7.9 \\
\hline Uterine perforation & 1 & 2.6 \\
\hline
\end{tabular}

Table 2 describes the procedure undertaken during repeat surgery. Haemostatic suture was main procedure done. Blood products used for patients undergoing relaparotomy were, packed red blood cells $(7.2$ $\pm 5.4)$, fresh frozen plasma $(4.3 \pm 5.5)$ and platelets $(1.2 \pm 2.3)$ units.

Table 3shows comparison according to duration between primary operation and relaparotomy.

Third operation was done in seven $(18.4 \%)$ cases. Indications were atonic uterus in two cases, continuous vaginal bleeding in two cases, one case was opened for rectus sheath hematoma and one to remove abdominal pack while in one patient resuturing of abdominal incision was done because of post laparotomy wound infection with gaping. Of 38 patients, 18 (47.4\%) recovered smoothly and were discharged from the hospital in good condition. Our 8/38 (21.1\%) cases needed referral for intensive care. Of them, five patients recovered and three $(7.89 \%)$ expired. Twelve $(31.6 \%)$ cases developed complications in post-operative period (Table 4). Average stay in hospital was 9.4 days with the range of $2-19$ days.

\section{Discussion}

Relaparotomy is beneficial in cases of intra-peritoneal and rectus sheath haemorrhage.

Table 2: Procedure performed in $2^{\text {nd }}$ and $3^{\text {rd }}$ relaparotomy $(n=38)$.

\begin{tabular}{|l|c|c|c|c|}
\hline \multirow{2}{*}{\multicolumn{2}{|c|}{ Procedure }} & \multicolumn{2}{c|}{$2^{\text {nd }}$ operation } & \multicolumn{2}{c|}{$3^{\text {rd }}$ operation } \\
\cline { 2 - 5 } & Patient $(\mathrm{n}=38)$ & Percentage & Patient $(\mathrm{n}=7)$ & Percentage \\
\hline Haemostatic sutures & 16 & 42.1 & & \\
\hline Resuturing of incision line & 14 & 36.8 & & 28.6 \\
\hline Hysterectomy & 5 & 13.1 & 1 & 14.3 \\
\hline Haematoma drainage & 3 & 7.9 & & \\
\hline Vascular repair by vascular surgeon & 3 & 7.9 & & 28.6 \\
\hline Rectus muscle haematoma drainage & 2 & 5.3 & & \\
\hline B-lynch suture & 2 & 5.3 & & \\
\hline Internal iliac artery ligation & 2 & 5.3 & & \\
\hline Uterine repair & 1 & 2.6 & & 14.3 \\
\hline Unilateral oophorectomy & 1 & 2.6 & & 14.3 \\
\hline Removal of abdominal packing & & & & \\
\hline Resuturing of gape wound & & & & \\
\hline
\end{tabular}


Table 3: Comparison according to duration between primary operation and relaparotomy.

\begin{tabular}{|l|l|l|l|}
\hline \multicolumn{1}{|c|}{ Variables } & $\begin{array}{c}<10 \text { Hours } \\
\mathrm{n}=22\end{array}$ & \multicolumn{1}{c|}{$\begin{array}{c}>10 \text { Hours } \\
\mathrm{n}=16\end{array}$} & $\mathrm{p}$-value \\
\hline Stay in hospital (days) & $8.5 \pm 5.2$ & $10.38 \pm 4.9$ & 0.27 \\
\hline Packed red blood cells & $8.5 \pm 6.5$ & $5.3 \pm 4.4$ & 0.09 \\
\hline Fresh frozen plasma (units) & $5.8 \pm 6.6$ & $2.3 \pm 2.7$ & 0.05 \\
\hline Platelets (units) & $1.3 \pm 2.5$ & $1.1 \pm 2.2$ & 0.79 \\
\hline Primary surgery blood loss (ml) & $1296 \pm 1183$ & $900 \pm 573$ & 0.22 \\
\hline Time of primary surgery (min) & $65 \pm 45$ & $68 \pm 28.3$ & 0.80 \\
\hline Second surgery blood loss (ml) & $1864 \pm 1027$ & $1513 \pm 829$ & 0.26 \\
\hline Time of second surgery (min) & $112 \pm 102$ & $69 \pm 23$ & 0.09 \\
\hline Post-operative Hb (g/dL) & $11.2 \pm 1.6$ & $9.1 \pm 0.6$ & 0.0001 \\
\hline $3^{\text {rd } \text { operation required }}$ & $22.7 \%$ & $12.5 \%$ & 0.045 \\
\hline Mortality & $18.1 \%$ & $12.5 \%$ & 0.21 \\
\hline
\end{tabular}

Table 4: Complications of relaparotomy in $\mathrm{n}=$ 12 cases in post-operative period.

\begin{tabular}{|l|c|c|}
\hline \multicolumn{1}{|c|}{ Complication } & $\mathrm{n}=12$ & Percentage \\
\hline Needed mechanical ventilation & 3 & 25 \\
\hline Acute renal failure & 2 & 16.7 \\
\hline Ureteric injury, referred to urologist & 3 & 25 \\
\hline Intra-abdominal haematome, jaundice & 1 & 8.3 \\
\hline Retention of Foleys catheter for $>10$ days & 3 & 25 \\
\hline
\end{tabular}

\section{Incidence}

In the current study, out of 8820 surgeries, $0.43 \%$ cases required reoperation. In our hospital, out of 5184 caesarean deliveries, CS rate was found $42 \%$, and relaparotomy as $0.55 \%$. In consistent with our findings, most of the researchers reported a relaparotomy rate as $0.5 \%-0.7 \%$ after CS deliveries. ${ }^{4,7,8}$ One study conducted in a teaching hospital of Ghana with a CS rate of $17 \%$ out of 36012 deliveries, revealed a relaparotomy rate of $0.7 \% .^{8}$ Another work from India consisting of 12967 deliveries with a CS rate of $34.8 \%$, described a relaparotomy rate of $0.33 \%$. The incidence of relaparotomy after gynecological surgeries was reported as $1.56 \%$ by Seal $^{4}$ and $0.77 \%$ by Dasgupta from India. ${ }^{9} \mathrm{We}$ observed this incidence as $0.24 \%$ which is significantly lower than above mentioned reports. This difference in relaparotomy rate could be justified by better monitoring facilities, in time and easy availability of blood/blood products and good clinical experience of doctors working in this teaching set up enab- ling them in a better way to monitor patients haemodynamically as compared to small facilities in which relaparotomy is considered to be, both diagnostic and lifesaving.

\section{Risk Factors}

In the present study CS was found to be the commonest indication 28/38 (73.7\%) of primary operation. Of CS, 13/38 (34.2\%) had primary surgery because of multiple CS and second most common reason was placenta previa. Reoperation data after caesarean deliveries is scant because most of the investigations focus on risk factors for peripartum caesarean hysterectomy. As expected, significant risk factors for obstetrical hysterectomy were placenta accrete and uterine atony with PPH. ${ }^{10,11}$ In case of placenta previa, both in first as well as repeat CS, haemostasis from placental bed should be properly secured before closing the uterine incision. In cases of doubt about haemostasis, before closing peritoneal cavity surgeon must examine the 
vagina to rule out bleeding. ${ }^{4}$ Complicated surgery like multiple repeat CS is associated with a higher risk of relaparotomy. This is current study's finding and needs large scale investigations to be proved.

\section{Indications}

The major indication for repeat surgery was found haemodynamic instability due to suspicion of intraabdominal haemorrhage. This is replication of previous studies. ${ }^{7,8}$ Bleeding source can be hypogastric, epigasteric or uterine arteries etc. In $70.8 \%$ cases of reoperation, significant bleeding and haematoma were found to be possible cause. ${ }^{3}$ Hemorrhage was observed a frequent and a leading indication of reoperation in many investigations, ${ }^{1,4}$ including Ghana study ${ }^{8}$ accounting for $58 \%$ of relaparotomies while another author reported it as $60.7 \% .^{12}$ In the current study, $63.2 \%$ patients had intra-abdominal haematoma but in some cases, origin of bleeding remained undetected. This is commonly faced situation in which after drainage/ evacuation of blood, surgeon is unable to locate the source of bleeding. Uterine scar bleeding (36.8\%) and broad ligament haematoma $(21.05 \%)$ were other common indications of relaparotomy. We observed bleeding along the incision line, especially at the corners due to loose knots or loose sutures. So, special attention should be paid to secure haemostasis while closing the uterine incision and it should be ensured before parietal peritoneum closure, during surgery. If surgeons pay optimum attention at the time of primary surgery, majority of the causes of relaparotomy are preventable and avoidable.

Similar to others, ${ }^{3,13,14}$ this study also described rectus sheath hematoma, another indication $(13.1 \%)$ of reoperation. Its incidence can be minimized by ensuring proper hemostasis before closing the rectus sheath during surgery. In consistent with our observation, Akhtar et al, ${ }^{13}$ demonstrated restlessness, tachycardia, hypotension and fall in the haemoglobin, as indicators of suspected concealed haemorrhage.

\section{Procedures Done in Relaparotomy:}

In our institution relaparotomies were performed by expert surgeons. Bleeding was controlled in $42 \%$ patients by haemostatic sutures. Almost similar to Seal et $\mathrm{al}^{4}{ }^{4}$ our $37 \%$ patients needed resuturing of uterine incision line, $13.1 \%$ ended up with hysterectomy and $18 \%$ needed third laparotomy.

\section{Mortality}

Post-operative management is very crucial because majority of patients died within 18 hours of repeat surgery. ${ }^{13}$ Maternal mortality was reported significantly high in cases who needed relaparotomy after $\mathrm{CS}^{5}$ It was reported $9 \%$ in the African ${ }^{15}$ and $12 \%$ in Indian series ${ }^{8}$ while we noted this finding as $8 \%$. In consistent with a report, we found mortality in obstetric reoperations as $6.6 \% .{ }^{14}$ Replicating Dasgupta's results ${ }^{9}$ mortality in gynaecological reoperations was observed as $12.5 \%$. We have limited intensive care facilities and patients are referred to higher center for ventilatory support and other intensive care facilities. This mortality rate can be minimized by careful primary surgery, early relaparotomy and availability of optimum intensive care facilities in the same hospital. Reoperation as a result of haemorrhage and wound dehiscence was associated with a lower rate of mortality as compared to septic patients. ${ }^{3}$

Our results show that patients having relaparotomy within 10 hours after primary operation needed more transfusion of blood products indicating, vitals instability as a result of intra-peritoneal haemorrhage diagnosed by ultrasonography, so the decision to reopen was taken early. Significantly increased requirement of third surgery ( $p$ value $<0.05$ ) and duration of second surgery in those patients was more, probably due to complicated procedure. Blood loss in the same patients group was more explaining the requirement of more blood / blood products. We observed high mortality in those patients which is probably due to their serious condition. Unexpectedly, the hospital stay of those patients was comparatively less indicating their smooth recovery. Mean post-operative haemoglobin was also better in early reoperated patients as they had more blood transfusions. All these findings indicate the better facilities, timely decision, proper care and availability of experienced surgeons in our tertiary care center.

Limitations of the current study were common possible hidden confounding factors which usually affect alike retrospective studies. Similarly, the number of patients in the study was too small to enable definite conclusion to be drawn.

\section{Suggestions and Recommendations:}

The incidence of relaparotomy is $0.43 \%$ and associated mortality is $8 \%$. Previous multiple CS is the main risk factor for relaparotomy. So, efforts to reduce 
CS rate may minimize the overall rate of complications including reoperation. We suggest:

1. Proper judgment, diagnosis, meticulous surgery, aseptic measure, optimum haemostasis, easy availability of required blood/blood products and safe anesthesia may minimize the incidence of this terrible situation.

2. All obstetricians must be competent enough, not to perform only simple caesarean sections but also to deal effectively the different complications related to the surgeries.

3. Indications of primary procedures whether gynaecological or obstetrical, patient's preoperative assessment, surgeon's competency, identification of high risk patients, early referral when needed for primary situation and prompt management by intensivist may impact the outcome of relaparotomies.

\section{Conclusion}

It is better to anticipate the probabilities of post operative intra peritoneal hamorrhage rather than treat them but at the same time the earliest signs in these critical cases must be closely monitored and investigated so as to avoid morbidity and mortality related to late reoperation.

\section{Conflict of Interest}

The authors have no conflicts of interest.

\section{References}

1. Kirk RM. Reoperative surgery for early complications following abdominal and abdomino-thoracic operations. J R Soc Med. 1988; 81: 7-9.

2. Gunther K, Taubert E, Mehwald J. Disordered postoperative course. A retrospective analysis. Zentralbl Chir. 1988; 113: 384-90.
3. Erdal SM, Abdulkadir T, Siddik EM, Ender SH, Ali O, Sibel S et al. Relaparotomy after initial surgery in obstetric and gynecologic operations: analysis of 113 cases. Ginekol Pol. 2012; 83: 429-32.

4. Seal SL, Kamilya G, Bhattacharyya SK, Mukherji J and Bhattacharyya AR. Relaparotomy after Cesarean Delivery: Experience from an Indian Teaching Hospital. J Obstet Gynaecol Res. 2007; 33 (6): 804-9.

5. Unalp HR, Kamer E, Kar H. Urgent abdominal reexplorations. World J Emerg Surg. 2006; 1:10.

6. Unalp H, Kamer E, Onal M. Analysis of early relaparotomy after lower gastrointestinal system surgery. Surg Today, 2008; 38: 323-8.

7. Lurie S, Sadan O, Golan A. Re-laparotomy after cesarean section. Eur J Obstet Gynecol Reprod Biol. 2007; 134 (2): 184-7.

8. Seffah JD. Re-laparotomy after Cesarean section. Int J Gynecol Obstet. 2005; 88 (3): 253-7.

9. Dasgupta S, Pratim SP, Aradhana K, Partha M, Karti M. Early re-operations after gynecological and obstetrical surgery - a five years. J Obstet Gynecol India, 2010; 60 (6): 507-10.

10. Kwee A, Bots ML, Visser GH, Bruinse HW. Bruinse. Emergency peripartum hysterectomy: A prospective study in The Netherlands. Eur J Obstet Gynecol Reprod Biol. 2006; 124 (2): 187-92.

11. Demirci O, Tuğrul AS, Yilmaz E, Tosun Ö, Demirci E, Eren YS. Emergency peripartum hysterectomy in a tertiary obstetric center: nine years evaluation. J Obstet Gynecol Res. 2011; 37 (8): 1054-60.

12. Levin I, Avital S, Rapaport, Satzer L, Maslovitz S, Joseph B et al. Risk factors for relaparotomy after cesarean delivery. Int J Gynecol Obstet. 2012; 119: 163-5.

13. Akther R, Hossain T, Rashid M. Relaparotomy after cesarean delivery: A prospective study. J Dhaka Med Coll. 2011; 20 (1): 57-62.

14. Alam IP, Mahabuba, Das SR. Relaparotomy in Obstetrics and Gynaecology Department of Faridpur Medical College Hospital - Experience in One Year. Faridpur Med. Coll. J. 2012; 7 (2): 75-8.

15. Ahmed S, Khanum PA, Islam A. Maternal morbidity in rural Bangladesh: where do women go for care? [WP113, 1998] ICDDR, B publication. 